\title{
Estimation of conditional asset pricing models with integrated variables in the beta specification
}

\author{
Antonios Antypas $^{\mathrm{a}}$, Guglielmo Maria Caporale ${ }^{\mathrm{b}, \mathrm{c}, \mathrm{d}}$, Nikolaos Kourogenis ${ }^{\mathrm{a}, *}$, \\ Nikitas Pittis ${ }^{\mathrm{a}}$ \\ ${ }^{a}$ Department of Banking and Financial Management, University of Piraeus, Greece \\ ${ }^{\mathrm{b}}$ Department of Economics and Finance, Brunel University London, UK \\ ${ }^{\mathrm{c}}$ CESifo, Munich, Germany \\ ${ }^{\mathrm{d}}$ DIW Berlin, Germany
}

\section{A R T I C L E I N F O}

\section{JEL classification:}

G1

G23

C1

\section{Keywords:}

Conditional CAPM

Time-varying beta

Cointegration

Morningstar star-rating system

\begin{abstract}
A B S T R A C T
We introduce a methodology which deals with possibly integrated variables in the specification of the betas of conditional asset pricing models. In such a case, any model which is directly derived by a polynomial approximation of the functional form of the conditional beta will inherit a nonstationary right hand side. Our approach uses the cointegrating relationships between the integrated variables in order to maintain the stationarity of the right hand side of the estimated model, thus, avoiding the issues that arise in the case of an unbalanced regression. We present an example where our methodology is applied to the returns of funds-of-funds which are based on the Morningstar mutual fund ranking system. The results provide evidence that the residuals of possible cointegrating relationships between integrated variables in the specification of the conditional betas may reveal significant information concerning the dynamics of the betas.
\end{abstract}

\section{Introduction}

The Capital Asset Pricing Model (CAPM), proposed by Treynor (1962), Sharpe (1964) and Lintner (1965), has been a cornerstone of the modern asset pricing theory. This model postulates that the expected excess return, $E\left(R_{j}-R_{f}\right)$, on asset $j$, (that is, the expected return $R_{j}$ minus the known risk-free rate $\left.R_{f}\right)$ is linearly related to the 'beta', $\beta_{j}$, of asset $j, \beta_{j} \equiv \operatorname{Cov}\left(R_{j}, R_{m}\right) / \operatorname{Var}\left(R_{m}\right)$ where $R_{m}$ denotes the returns on the market portfolio and $E\left(R_{j}-R_{f}\right)=\beta_{j} E\left(R_{m}-R_{f}\right)$. Since the inception of CAPM, numerous asset pricing models have been developed, such as the Single Factor Model and its multivariate generalization, the Multiple Factor Model, the Arbitrage Pricing Model (Ross, 1976) and the Intertemporal Capital Asset Pricing Model (Merton, 1973). These models have inspired the development of a large number of variations or extensions.

One common assumption used in the aforementioned models, is that of linear relationships between the (excess) return of asset $j$ and the corresponding risk factors. For the estimation of these models, it was initially assumed that the slope coefficients (the betas) remain constant over time, or over the estimation window. There is, however, overwhelming evidence suggesting that betas are not constant over time. Important studies supporting the hypothesis of a time-varying beta, $\beta_{j, t}$, include Blume (1971), Blume (1975), Fabozzi and Francis (1978), Sunder (1980), Ohlson and Rosenberg (1982), Bos and Newbold (1984), Fisher and Kamin (1985),

\footnotetext{
* Corresponding author. Address: Department of Banking and Financial Management, University of Piraeus, 80 Karaoli \& Dimitriou Str., 18534 Piraeus, Greece.

E-mail addresses: aantypas@unipi.gr (A. Antypas), Guglielmo-Maria.Caporale@brunel.ac.uk (G.M. Caporale), nkourog@unipi.gr (N. Kourogenis),npittis@unipi.gr (N. Pittis).
} 
Collins et al. (1987), Bos and Fetherston (1992), Bos and Fetherston (1995) and Faff et al. (1992). The findings of these studies motivated the examination of models of time varying betas (see, e.g., Shanken, 1990; Jagannathan and Wang, 1996; Ferson and Schadt, 1996; Lettau and Ludvigson, 2001).

Under the assumption that the dynamic behavior of the betas depends on the variation of a set of observed variables, Shanken (1990) and Ferson and Schadt (1996) used conditional versions of the CAPM. Specifically, let

$$
\begin{aligned}
& r_{j, t+1}=b_{j}\left(Z_{t}\right) r_{m, t+1}+u_{j, t+1} \\
& E\left(u_{j, t+1} \mid Z_{t}\right)=0 \\
& E\left(u_{j, t+1} r_{m, t+1} \mid Z_{t}\right)=0
\end{aligned}
$$

where $r_{j, t}=R_{j, t}-R_{f, t} Z_{t}=\left[Z_{1, t}, Z_{2, t}, \ldots, Z_{n, t}\right]^{\prime}$ is an $n$-vector of state variables observable at time $t$, and $r_{m, t}=R_{m, t}-R_{f, t}$. This specification implies that the systematic risk of the asset $j$, as measured by $b_{j}\left(Z_{t}\right)$, changes over time.

Because the functional form of $b_{j}(\cdot)$ is unknown, model (1)-(3) cannot be directly estimated. It is, however, usual to approximate $b_{j}(\cdot)$ by a first- or second-order Taylor series expansion (see, e.g., Shanken, 1990; Ferson and Schadt, 1996; Jiang et al., 2007; Clare et al., 2016; Chen and Chi, 2018). To estimate the resulting 'approximate' model, it is naturally assumed that the left hand side variable, $r_{j, t+1}$, as well as $r_{m, t+1}$ are stationary. This assumption imposes restrictions on the selection of the variables included in $Z_{t}$ so that the right hand side of the approximate model remains stationary. For example, if $n=1$ and $Z_{t}$ is $I(1)$, then we will face the problem of an unbalanced regression because both conditional and unconditional variances of the right hand side of the model will be explosive. In general, this may be the case if some (or all) of the variables in $Z_{t}$ are integrated.

In the next section we propose a methodology that allows us to exploit possible relationships between integrated variables, so that their inclusion in $Z_{t}$ does not violate the stationarity requirement. In the third section we apply our methodology to the returns of funds-of-funds which are created with respect to the star-rating system of Morningstar. The fourth section concludes the paper.

\section{Integrated variables in the beta specification}

As pointed out in the previous section, the inclusion of integrated variables in the specification of the conditional betas can lead us to spurious conclusions. In this section we present a methodology for the appropriate treatment of these variables. For expository simplicity we use a simple one factor model. Our methodology, however, can be directly extended to multiple factor models because the approximations of the functional forms of each beta are treated separately.

\subsection{Formalization and treatment of the problem}

Let us begin by using a first order approximation of $b_{j}$ in Eq. (1). We obtain

$$
r_{j, t+1}=\beta_{j, 0}+\beta_{j}^{c} r_{m, t+1}+r_{m, t+1} \sum_{i=1}^{n} \beta_{j, i} Z_{i, t}+u_{j, t+1}
$$

It is quite natural to assume that both $r_{j, t+1}$ and $r_{m, t+1}$ in (4) are stationary. On the other hand, this cannot be a priori assumed for $Z_{1, t}$ $Z_{2, t}, \ldots, Z_{n, t}$. Therefore, we must first analyze in detail the alternative models (all based on (4)) that arise depending on the statistical properties of the variables $Z_{1, t}, Z_{2, t}, \ldots, Z_{n, t}$. Specifically, we distinguish three cases:

(i) The vector stochastic process $\left[r_{m, t+1} ; Z_{t}^{\prime}\right]^{\prime}$ is stationary. This implies that the new variables $Z_{i, t} r_{m, t+1}$ will also be $I(0)$ (given that the market returns variable $r_{m, t+1}$ is quite naturally $I(0)$ ), and Eq. (4) is legitimate since $r_{j, t+1}$ is also quite naturally $I(0)$ ).

(ii) Some (or all) of the variables $Z_{1, t}, Z_{2, t}, \ldots, Z_{n_{0}, t}, n_{0} \leq n$ are $I(1)$ and not cointegrated. In this case, the product variables $Z_{i, t} r_{m, t+1}, i=1,2, \ldots, n_{0}$ will have an asymptotically unbounded unconditional variance and will not be $I(0)$. In such a case, we have the problem of an unbalanced regression since the dependent variable, $r_{j, t+1}$ is $I(0)$.

(iii) Some (or all) of the variables $Z_{1, t}, Z_{2, t}, \ldots, Z_{n_{0}, t}, n_{0} \leq n$ are $I(1)$ and cointegrated. In this case, we proceed as follows:

Eq. (4) shows that under the assumption that the returns processes $\left\{r_{j, t}\right\}_{t \geq 1}$ and $\left\{r_{m, t}\right\}_{t \geq 1}$ are $I(0)$, the only case where some of the $Z_{i, t}$ can be $I(1)$ is when the corresponding coefficients are such that only multiples of the cointegration relations between those $Z_{i, t}$ that are cointegrated are left on the right-hand side of (4). The following example highlights differences between case (ii) and case (iii): Let

$$
r_{j, t+1}=\beta_{j, 0}+\beta_{j}^{c} r_{m, t+1}+\left(\beta_{j, 1} Z_{1, t}+\beta_{j, 2} Z_{2, t}\right) r_{m, t+1}+u_{j, t+1}
$$

If $Z_{1, t}$ and $Z_{2, t}$ are not cointegrated and $\beta_{j, 1} \beta_{j, 2} \neq 0$, the unconditional variance of the right-hand side will grow to infinity as $t \rightarrow \infty$, violating our initial assumption that the unconditional variance of $r_{j, t+1}$ is bounded. Therefore the estimated values of $\beta_{j, 1}$ and $\beta_{j, 2}$ will be very close to 0 when the sample is large. If, on the other hand, $Z_{1, t}$ and $Z_{2, t}$ are cointegrated and satisfy

$$
Z_{1, t}=a_{0}+a_{1} Z_{2, t}+w_{t}
$$

where $\left\{w_{t}\right\}_{t \geq 1}$ is $I(0)$, the only way for the unconditional variance of $\beta_{j, 1} Z_{1, t}+\beta_{j, 2} Z_{2, t}$ to remain asymptotically bounded, with nonzero $\beta_{j, 1}$ and $\beta_{j, 2}$, is the case where

$$
\beta_{j, 1} Z_{1, t}+\beta_{j, 2} Z_{2, t}=\lambda\left(Z_{1, t}-a_{1} Z_{2, t}\right)=\lambda\left(a_{0}+w_{t}\right), \quad \lambda \in \mathbb{R}
$$


The last equation implies that $\beta_{j, 1}=\lambda$ and $\beta_{j, 2}=-a_{1} \beta_{j, 1}$. If we identify the cointegrating relationship between $Z_{1, t}$ and $Z_{2, t}$, then we can rewrite (5) as

$$
r_{j, t+1}=\beta_{j, 0}+\beta_{j}^{c} r_{m, t+1}+\beta_{j, 1} q_{1, t} r_{m, t+1}+u_{j, t+1}
$$

where $q_{1, t}=Z_{1, t}-a_{1} Z_{2, t}=a_{0}+w_{t}$.

The previous example demonstrates that it is necessary for the sum $\sum_{i=1}^{n} \beta_{j, i} Z_{i, t}$ in (4) to be I(0) in order for (4) to be a legitimate regression. It also suggests how to treat the initial set of candidate state variables, in order to obtain in (4) a well-balanced regression. Specifically, the following steps must be taken:

First, we identify all the state variables (elements of $Z_{t}$ ) that are $I(1)$. Assume that the number of such $I(1)$ variables is $n_{0}$. If $n_{0}>0$, without loss of generality, reordering the variables if necessary, we can make sure that, for $i \leq n_{0},\left\{Z_{i, t}\right\}_{t \geq 1}$ are $I(1)$ and, for $n_{0}<i \leq n,\left\{Z_{i, t}\right\}_{t \geq 1}$ are $I(0)$. Second, we identify any cointegrating relationships between the processes $\left\{Z_{i, t}\right\}_{t \geq 1}, 1 \leq i \leq n_{0}$. Let $k<n_{0}$ be the rank of the cointegrating system. This means that we can find a $\left(k \times n_{0}\right)$ matrix $A$ of order $k$, such that

$$
A\left[Z_{1, t}, Z_{2, t}, \ldots, Z_{n_{0}, t}\right]^{\prime}=U_{t}
$$

where $\left\{U_{t}\right\}_{t \geq 0}$ is $I(0)$ with nontrivial coordinates $U_{i, t}, 1 \leq i \leq k$. Again, without any loss of generality, we can reorder the variables $Z_{i, t}$, $1 \leq i \leq n_{0}$ in (4), so that the first $k$ columns of $A$ are linearly independent. Therefore, we can write $A=\left[A_{1}, A_{2}\right]$, where the $k \times k$ matrix $A_{1}$ is invertible. Then, left multiplication of (7) by $A_{1}^{-1}$ yields

$$
\left[I_{k}, A_{1}^{-1} A_{2}\right] Z_{t}=A_{1}^{-1} U_{t}
$$

which in turn gives

$$
\left[Z_{1, t}, Z_{2, t}, \ldots, Z_{k, t}\right]^{\prime}=-A_{1}^{-1} A_{2}\left[Z_{k+1, t}, Z_{k+2, t}, \ldots, Z_{n_{0, t}}\right]^{\prime}+A_{1}^{-1} U_{t}
$$

The last equation is the first part of Phillips's triangular system (Phillips, 1991). The second part of this system is

$$
\left[\Delta Z_{k+1, t}, \Delta Z_{k+2, t}, \ldots, \Delta Z_{n 0, t}\right]^{\prime}=V_{t}
$$

where $V_{t}$ is also $I(0)$. Eqs. (7) and (9) provide us with $n_{0} I(0)$ processes that can be considered as state variables in a new regression, replacing the $Z_{i, t}, 1 \leq i \leq n_{0}$. Third, having defined the appropriate set, $W_{t}$, of $I(0)$ state variables,

$$
W_{t}=\left(W_{i, t}\right)_{1 \leq i \leq n}=\left[U_{1, t}, U_{2, t}, \ldots, U_{k, t}, \Delta Z_{k+1, t}, \ldots, \Delta Z_{n_{0}, t}, Z_{n_{0}+1, t}, \ldots, Z_{n, t}\right]^{\prime}
$$

we can run the following regression

$$
r_{j, t+1}=\beta_{j, 0}^{*}+\beta_{j}^{c} r_{m, t+1}+\sum_{i=1}^{k} \beta_{j, i}^{*} U_{i, t} r_{m, t+1}+\sum_{i=k+1}^{n_{0}} \beta_{j, i}^{*} \Delta Z_{i, t} r_{m, t+1}+\sum_{i=n_{0}+1}^{n} \beta_{j, i}^{*} Z_{i, t} r_{m, t+1}+u_{j, t+1}
$$

This regression can be rewritten in a more compact form in terms of $W_{t}$ as

$$
r_{j, t+1}=\beta_{j, 0}^{*}+\beta_{j}^{c} r_{m, t+1}+\sum_{i=1}^{n} \beta_{j, i}^{*} W_{i, t} r_{m, t+1}+u_{j, t+1}
$$

or simply

$$
r_{j, t}=\beta_{j, 0}^{*}+\beta_{j}^{c} r_{m, t+1}+\sum_{i=1}^{d} \beta_{j, i}^{*} X_{i, t}+\zeta_{j, t}
$$

where $X_{i, t}=W_{i, t-1} r_{m, t}$ for $1 \leq i \leq n$. The regression defined in (11) can be considered a first-order approximation of the general model given by

$$
r_{j, t+1}=\beta_{j, 0}^{*}+\beta_{j}^{*}\left(W_{t}\right) r_{m, t+1}+\varepsilon_{i, t+1}^{*}
$$

which involves only $I(0)$ processes.

The preceding discussion is based on approximating the unknown function $b_{j}\left(Z_{t}\right)$, or equivalently $\beta_{j}^{*}\left(W_{t}\right)$, by using a first-order Taylor series expansion. Alternatively, we can approximate $\beta_{j}^{*}\left(W_{t}\right)$ by using a second-order Taylor expansion. In such a case we have

$$
r_{j, t+1}=\beta_{j, 0}^{*}+\beta_{j}^{c} r_{m, t+1}+\sum_{i=1}^{n} \beta_{j, i}^{*} W_{i, t} r_{m, t+1}+\sum_{1 \leq i \leq k \leq n} \beta_{j, i, k}^{*} W_{i, t} W_{k, t} r_{m, t+1}+\zeta_{j, t+1}
$$

The last equation involves $n+\left(\begin{array}{l}n \\ 2\end{array}\right)=\frac{n(n+1)}{2} \triangleq d$ explanatory variables of the form $W_{i, t} r_{m, t+1}$ or $W_{i, t} W_{k, t} r_{m, t+1}, 1 \leq i \leq k \leq n$, which can be denoted as $X_{l, t+1}, 1 \leq l \leq d$.

We can rewrite (14) as:

$$
r_{j, t}=b_{j, 0}+\beta_{j}^{c} r_{m, t+1}+\sum_{i=1}^{d} b_{j, i} X_{i, t}+\zeta_{j, t}
$$


Table 1

Explosive behavior of a returns process when the conditional beta is not stationary.

\begin{tabular}{lll}
\hline Sample size & Average s.d. $\left(y_{1}\right)$ & Average s.d. $\left(y_{2}\right)$ \\
\hline 50 & 1.11 & 2.48 \\
100 & 1.11 & 3.36 \\
500 & 1.12 & 7.03 \\
1000 & 1.12 & 9.86 \\
2000 & 1.12 & 13.93 \\
5000 & 1.12 & 21.81 \\
10,000 & 1.12 & 30.94 \\
\hline
\end{tabular}

where $b_{j, 0}=\beta_{j, 0}^{*}, b_{j, i}=\beta_{j, i}^{*}$ and $X_{i, t}=W_{i, t-1} r_{m, t}$ for $1 \leq i \leq n, b_{j, i}=\beta_{j, g, h}^{*}$ and $X_{i, t}$ is of the form $W_{g, t-1} W_{h, t-1} r_{m, t}$, when $n+1 \leq i \leq d$, for some $1 \leq g, h \leq n$.

\subsection{A small simulation study}

The previous subsection developed our argument about the requirement that the additive terms of the polynomial approximation of $b_{j}$ must be stationary. A very simple simulation study demonstrates the way the stationarity assumption on the left hand side variable in (4) is violated when this requirement is not satisfied. To this end, let $\left\{Z_{1, t}\right\}$ be generated by $Z_{1, t+1}=Z_{1, t}+v_{t+1}, t \geq 0$, $Z_{1,0}=0$, while $\left\{v_{t}\right\}_{t \geq 1}$ are independent $N(0,1)$. By construction, $\left\{Z_{1, t}\right\}$ is I(1). Within our very simplified setting, let us assume that the market returns process $\left\{r_{m, t}\right\}_{t \geq 1}$ is also independent $N(0,1)$. We will consider to returns processes, $y_{1, t}$ and $y_{2, t}$. The generating mechanism of the first one involves multiplication of $r_{m, t+1}$ by the first differences of $Z_{1, t}, \Delta Z_{1, t}=Z_{1, t}-Z_{1, t-1}$, while the generating mechanism of $y_{2, t}$ involves multiplication of $r_{m, t+1}$ by $Z_{1, t}$ itself. Specifically, the equations that describe these generating mechanisms are the following:

$$
y_{1, t+1}=0.5 \Delta Z_{1, t} r_{m, t+1}+v_{t+1}
$$

and

$$
y_{2, t+1}=0.5 Z_{1, t} r_{m, t+1}+v_{t+1}
$$

where the $\left\{v_{t}\right\}_{t \geq 1}$ are independent $N(0,1)$. We generate 5000 replications for $y_{1}$ and $y_{2}$ and we estimate their sample standard deviations for sample sizes ranging from 50 to 10,000. For each sample size, the average of these estimates over the 5000 replications is presented in Table 1 .

As theoretically expected, Table 1 supports the explosive behavior of the sample standard deviation of $y_{2}$, and consequently its non-stationarity. The explosive non-stationarity implied by the right hand side in (17) is clearly not compatible to the stylized facts of financial returns. Note that the stationarity of the right hand side in (16) is guaranteed since $\Delta Z_{1, t} r_{m, t+1}=v_{t} r_{m, t+1}$ is stationary. As explained in the previous subsection, the same holds when instead of $v_{t}$, we use as a multiplier the stationary linear combination of two or more $I(1)$ processes in the case that these processes are cointegrated and are involved in the functional form of $b_{j}(\cdot)$.

Next section provides an example of how our methodology can be applied using portfolios of funds (funds-of-funds) which are based on the Morningstar star-rating system.

\section{An application to funds-of-funds based on the Morningstar star-rating system}

This section aims to demonstrate how the methodology presented in the previous section can be implemented. To this end, we use Morningstar fund data, aiming to identify possible factors that a fund manager may consider when she/he adjusts the exposure of the corresponding portfolio to systematic risk (the portfolio's beta). The data used in our study were taken from Morningstar Direct, which provides historical monthly returns of mutual funds along with their star-based rankings calculated by Morningstar. The Morningstar 'star-rating' is a risk-adjusted performance measure, which ranges from one-star to five-stars (higher rating implying better risk-adjusted performance), and usually varies slowly over time.

In 2002, Morningstar modified the star rating system by introducing new peer groups and a new measure of risk-adjusted return (see Füss et al. (2010) for an informative brief description of the procedure used by Morningstar). This fact implied that incorporating data prior to July 2002 would add a significant heterogeneity factor in our sample. In order to avoid possible implications of this structural change, we cover the subsequent period (July 2002 to September 2018). We focus on the subset represented by US domiciled equity mutual funds that invest at least $90 \%$ of their Non-cash Adjusted Total Assets in equity securities around the world. To avoid dealing with currency risk exposure we only consider funds quoted in US Dollars.

Given the availability of the star-ratings, we proceed further in our investigation aiming to answer the question of whether different star-ratings correspond to different factors that appear to be significantly related to the corresponding funds' beta. To this end, we create five alternative portfolios of funds (funds-of-funds) with respect to the five star-rating categories. We first select funds purchased by large institutional investors. These funds correspond to the Morningstar share class type 'INST' and involve various share classes (4854 funds). In order, however, to properly demonstrate our methodology, we have to choose our dataset in a way that minimizes the effects of other funds' characteristics that may be correlated with the star-ratings. For example, five-star funds are 
predominantly Class A shares, while this is not true for one-star funds. This correlation may be a source of bias. ${ }^{1}$

Concerning the returns series for each fund, we choose the Gross Returns instead of the Net Returns, because our analysis focuses on the perspective of the fund manager. Specifically, according to Morningstar, "for open-end funds, Gross Returns are calculated by taking the Total Return and backing out the most recent Expense Ratio. Total Returns are determined by taking the change in price, reinvesting, if applicable, all income and capital gains distributions during the period, and dividing by the starting price. Morningstar does not adjust Total Returns for sales charges (such as front-end loads, deferred loads, and redemption fees). However, Total Returns do account for the expense ratio, which includes management, administrative, $12 \mathrm{~b}-1$ fees, and other costs that are taken out of assets." Thus, starting from the Total Returns and reversing the effect of the expense ratio, Morningstar calculates the Gross Returns. This returns series provides us a clearer performance from the fund manager perspective, because it is directly related to the performance of the constituents of the fund, and their corresponding weights in the allocation scheme that the fund manager has chosen.

In order to create the portfolios and the corresponding returns we proceed as follows: The first portfolio, named STAR1, consists of all the funds that in each time period, $t$, are rated one-star by Morningstar. Specifically, in period $t=1$ (the first period in our sample) we invest an amount A\$ in a portfolio consisting of all the funds (equally weighted) that have been given one-star by Morningstar in period $t=1$. In period $t=2$, the amount $\left(1+R_{1}^{1 *}\right) \times A\left(R_{1}^{1 *}\right.$ being the return of the portfolio between periods 1 and 2$)$ is invested again in a portfolio consisting solely of funds that in period 2 were rated one-star by Morningstar. We continue this process until we reach period $t=T$, i.e. the last period of our sample. In this way, we obtain a series of returns $R_{1}^{1 *}, R_{2}^{1 *}, \ldots, R_{T}^{1 *}$ generated by investing exclusively in one-star funds. These are interpreted as being a random vector from the process $\left\{R_{t}^{1 *}\right\}$ generating one-star portfolio returns. We repeat the same procedure for two-, three-, four- and five-star funds, thus obtaining samples from the returns processes $\left\{R_{t}^{2 *}\right\},\left\{R_{t}^{3 *}\right\},\left\{R_{t}^{4 *}\right\},\left\{R_{t}^{5 *}\right\}$, which are supposed to generate returns for the two-, three-, four- and five-star funds respectively. Finally, following how an investor acts when a fund stops performing, we exclude non-surviving funds from the allocation procedure after their exit of the Morningstar rating system.

\subsection{Identification of significant factors in the dynamics of conditional betas}

We consider an asset pricing model that describes the relationship between the expected return and risk of the various portfolios under consideration. Specifically, we adopt the conditional CAPM model of Ferson and Schadt (1996) and Shanken (1990) in which the level of the systematic portfolio risk is a function of the observed variables (see also, Lettau and Ludvigson, 2001). This in turn implies that the relationship between the excess returns of the portfolio $j$ and the excess returns of the market factor is given by the relationships (1)-(3), where, now, $r_{j, t}=R_{t}^{j *}-R_{f, t}, j=1,2, \ldots, 5, R_{f, t}$ is the return of a one-month Treasury bill, $Z_{t}=\left[Z_{1, t}, Z_{2, t}, \ldots\right.$, $\left.Z_{n, t}\right]^{\prime}$ is an $n$-vector of state variables observable by the managers at time $t$, and $r_{m, t}=R_{t}^{m}-R_{f, t}$ where $R_{t}^{m}$ stands for the returns of the market factor (returns on the S\&P 500). This specification implies that the systematic risk of the portfolio $j$, as measured by $b_{j}\left(Z_{t}\right)$, changes with time.

The time-varying nature of beta is due to the fact that the portfolio manager receives at time $t$ an "information signal", contained in the state variables $Z_{t}$ on the basis of which he changes the beta of his portfolio. If the signal is "correct" and the manager succeeds in "receiving" it, then the changes in the beta of the portfolio at time $t$ will be consistent with the realized returns $r_{m, t+1}$ at time $t+1$. To put it differently, if $r_{m, t+1}>0$ then the correct interpretation of the signal implies that the manager will shift the portfolio towards including stocks with high betas. The preceding discussion implies that the ability of the fund manager to "time" the market depends on the extent to which he/she can translate the information content of $Z_{t}$ into predictions on the future behavior of $r_{m, t+1}$. This does not necessarily mean that "everybody" in the market can "read" the information contained in $Z_{t}$. In other words, although the variables $Z_{t}$ are indeed publicly available, the information content of $Z_{t}$ might be available only to a 'skillful' fund manager.

As far as the selection of the variables in $Z_{t}$ is concerned, we follow Ferson and Schadt (1996), by including the 1-month Treasury bill yield, $z_{1}$, the term spread, $z_{2 t}$, defined as the difference between the constant-maturity 10-year Treasury bond yield and the 3month Treasury bill, the quality spread in the corporate bond market, $z_{6}$, defined as the Moody's BAA-rated corporate bond yield minus the AAA-rated corporate bond yield, the S\&P 500 dividend yield, $z_{8 t}$, and a dummy variable, $z_{9 t}$, for the January effect. In addition, we include variables that are usually considered important indicators by the financial community such as the price of oil, $z_{3 t}$, the weighted average of the foreign exchange value of the US dollar against a subset of the broad index currencies, $z_{4 t}$, the Consumer Sentiment Index of the University of Michigan, $z_{5 t}$, and the Chicago Board Options Exchange volatility index (VIX), $z_{7 t}{ }^{2}$

Finally, note that the above model can be augmented by the market timing term, $\gamma_{j} r_{m, t+1}^{2}$, proposed by Treynor and Mazuy (1966). A positive (negative) timing coefficient $\gamma_{j}$ is interpreted as evidence suggesting superior (inferior) market timing abilities of the corresponding fund manager.

\subsubsection{Time series properties of the state variables}

As explained in the previous section, the choice of the appropriate model for conditional portfolio evaluation depends on the statistical properties of the state variables $z_{1 t}, z_{2 t}, \ldots, z_{8 t}$, considering that $z_{9 t}$ is a dummy variable. The results from ADF and PhillipsPeron unit root tests, reported in Table $2 \mathrm{~A}$, unambiguously indicate that the first five series are $I(1)$, while $z_{6 t}, z_{7 t}, z_{8 t}$ are $I(0)$. In order to test the existence of cointegration relationships between $z_{1 t} z_{2 t}, z_{3 t}, z_{4 t}$ and $z_{5 t}$ we set the lag-length, $l$, of the vector autoregressive

\footnotetext{
${ }^{1}$ As a robustness check of the analysis concerning the 'INST' funds we conducted the same analysis for the funds in the A share class (3971 funds) reaching the same conclusions.

${ }^{2}$ The source of $z_{1 t}, z_{2 t}, z_{5 t}$ and $z_{6 t}$ is Bloomberg, of $z_{3 t}, z_{4 t}$ and $z_{7 t}$ is FRED St. Louis, and of $z_{7 t}$ is Standard's \& Poors.
} 
Table 2

Statistical properties of the state variables.

\begin{tabular}{llll}
\hline A. Unit root tests & & & \\
\hline Variable & ADF & P-P & \\
\hline$z_{1 t}$ & Constant & Trend \\
$z_{2 t}$ & -0.92 & -0.93 & $\mathrm{~N}$ \\
$z_{3 t}$ & -1.48 & -1.48 & $\mathrm{~N}$ \\
$z_{4 t}$ & -2.49 & -2.21 & $\mathrm{~N}$ \\
$z_{5 t}$ & -2.44 & -2.28 & $\mathrm{~N}$ \\
$z_{6 t}$ & -2.46 & -2.48 & $\mathrm{~N}$ \\
$z_{7 t}$ & $-3.79^{* * *}$ & $\mathrm{~N}$ & $\mathrm{Y}$ \\
$z_{8 t}$ & $-3.41^{* *}$ & $\mathrm{Y}$ & $\mathrm{Y}$ \\
\hline
\end{tabular}

B. Testing for cointegration among $z_{1 t}, z_{2 t}, \ldots, z_{5 t}$

\begin{tabular}{|c|c|c|c|c|}
\hline & \multicolumn{2}{|l|}{$l=4$} & \multicolumn{2}{|l|}{$5 \%$ c.v.'s } \\
\hline & $\lambda-\max$ & TR & $\lambda-\max$ & TR \\
\hline$k=0$ & 32.92 & 83.21 & 34.81 & 76.97 \\
\hline$k=1$ & 28.02 & 50.30 & 28.59 & 54.08 \\
\hline$k=2$ & 12.60 & 22.28 & 22.30 & 35.19 \\
\hline$k=3$ & 6.73 & 9.68 & 15.89 & 20.26 \\
\hline$k=4$ & 2.95 & 2.95 & 9.16 & 9.16 \\
\hline
\end{tabular}

$* * *: p$-value $<1 \%$; **: $1 \% \leq p$-value $<5 \%$; * $5 \% \leq p$-value $<10 \%$.

Notes: (1) $z_{1 t}=1$-month treasury bill yield, $z_{2 t}=$ constant-maturity 10 -year Treasury bond yield minus 3 -month Treasury bill, $z_{3 t}=$ the price of oil, $z_{4 t}=$ the exchange rate of the US dollar, $z_{5 t}=$ the consumer confidence index, $z_{6 t}=$ Moody's BAA-rated corporate bond yield minus AAA-rated corporate bond yield, $z_{7 t}=$ the CBOE's VIX volatility index, and $z_{8 t}=$ the S\&P 500 dividend yield. (2) ADF and P-P refer to the standard augmented Dickey-Fuller (Dickey and Fuller, 1979) and Phillips-Perron (Phillips and Perron, 1988) tests respectively for the null hypothesis of a unit root. The lag-length and the bandwidth parameter in ADF and P-P, respectively, were selected by the Schwarz information criterion and the Newey and West (1994) procedure respectively. (3) $l$ denotes the lag length of the unrestricted vector autoregressive model (VAR) based on which the Johansen (1991) maximum eigenvalue $(\lambda-\max )$ and trace (TR) statistics were calculated.

model, $\operatorname{VAR}(l)$ equal to 4. The results reported in Table 2B show that the trace (TR) statistic of Johansen (1991) identifies at most one cointegration relationship between the $I(1)$ state variables. On the other hand, under the hypothesis of no cointegration, the maximum eigenvalue $(\lambda-\max )$ statistic is slightly below the $5 \%$ critical value. As a result, we run two alternative conditional regressions assuming $k=0$ and $k=1$ (assuming $\operatorname{GARCH}(1,1)$ errors and including the market timing term $\gamma_{j} r_{m, t+1}^{2}$ ).

\subsubsection{Estimation results}

Concerning the identification of the cointegrating relationship when we assumed that $k=1$, we proceeded as follows: First, we searched between all combinations of the five $I(1)$ variables by four for the one whose trace statistic has the lowest $p$-value. We found that the most probable cointegrating relationship involves $z_{10} z_{3 t} z_{4 t}$ and $z_{5 t}$ with a corresponding $p$-value equal to 0.0511 . Since this $p$-value exceeds $5 \%$, one could claim that all five time series are included in the cointegrating relationship. However, because the $p$ value is only slightly over $5 \%$, it seems natural to check whether there is evidence of cointegration in a subset of three variables among $z_{1 t}, z_{3 t}, z_{4 t}$ and $z_{5 t}$. We proceed to the next step, which is to identify any possible cointegrating relationships that involve at most three of $z_{1 t}, z_{3 t}, z_{4 t}$ and $z_{5 t}$. Using the same $p$-value approach, we identify a relationship between $z_{3 t} z_{4 t}$ and $z_{5 t}$ with a corresponding $p$-value equal to 0.0372 . Since this $p$-value is lower than 0.05 we proceeded by searching for a cointegrating relationship between all possible pairs from $z_{3 t}, z_{4 t}$ and $z_{5 t}$. Then we identify a cointegrating relationship between $z_{3 t}$ and $z_{4 t}$ with a $p$ value of 0.0417 . We have used this relationship in our estimation, as described in the previous section.

The results presented in Table 3 correspond to the application of a general-to-specific approach, where we start from Eq. (11) and in each step all terms involving the factors $z_{i}, 1 \leq i \leq 9$, and having coefficients with a p-value greater or equal than 0.05 are omitted. Then the equation is re-estimated.

Table $3 \mathrm{~A}$ and $\mathrm{B}$ reports the results that correspond to the cases of zero and one cointegrating relationships. In addition, we present the results that correspond to the state variables used in Ferson and Schadt (1996) following their approach (i.e. without differencing the $I(1)$ variables). We focus on the identification of significant state variables in the beta specification. Specifically, we make the following observations:

(i) Only the dividend yield of the S\&P 500, $z_{8 t}$, appears to be statistically significant, and only for the STAR1 and STAR2 portfolios, when the approach of Ferson and Schadt (1996) is employed (Table 3C). ${ }^{3}$

\footnotetext{
${ }^{3}$ Unfortunately there is no evidence for any cointegrating relationship among the I(1) variables in Ferson and Schadt (1996). If, however, we take first differences we obtain identical results with the ones of Table 3A for the STAR1 and STAR2 portfolios. Because $z_{5 t}$ does not belong in the set of variables of Table 3C, there is no evidence of any significant variable for the STAR4 portfolio in this case.
} 
Table 3

Estimation of conditional models for the star-rated funds-of-funds (GARCH(1,1) error specification).

\begin{tabular}{|c|c|c|c|c|c|c|c|}
\hline Fund-of-funds & $a$ & $t(a)$ & $\gamma$ & $t(\gamma)$ & $\begin{array}{l}\text { Significant state variables } \\
(p \text {-value }<0.05)\end{array}$ & AIC & SIC \\
\hline \multicolumn{8}{|c|}{ A: Cointegration rank among $z_{1 t}, z_{2 t}, z_{3 t}, z_{4 t}$ and $z_{5 t}$ equals zero. $\Delta z_{1 t}, \Delta z_{2 t}, \Delta z_{3 t}, \Delta z_{4 t}, \Delta z_{5 t}, z_{6 t}, z_{7 t}, z_{8 t}$ and $z_{9 t}$ are employed as state variables. } \\
\hline STAR1 & 0.002 & 1.47 & -0.79 & -2.64 & $\Delta\left(z_{2 t-1}\right), z_{8 t-1}$ & -5.79 & -5.65 \\
\hline STAR2 & 0.002 & 2.50 & -0.50 & -1.92 & $\Delta\left(z_{2 t-1)}, z_{8 t-1}\right.$ & -6.04 & -5.90 \\
\hline STAR3 & 0.002 & 2.86 & -0.35 & -1.91 & - & -6.25 & -6.15 \\
\hline STAR4 & 0.003 & 3.60 & -0.57 & -2.16 & $\Delta\left(z_{5 t-1}\right)$ & -6.26 & -6.14 \\
\hline STAR5 & 0.003 & 2.72 & -0.51 & -1.42 & - & -6.00 & -5.90 \\
\hline \multicolumn{8}{|c|}{$\begin{array}{l}\text { B: Cointegration rank among } z_{1 t}, z_{2 t}, z_{3 t}, z_{4 t} \text { and } z_{5 t} \text { equals one. } u_{1 t}, \Delta z_{1 t}, \Delta z_{2 t}, \Delta z_{5 t}, z_{6 t}, z_{7 t}, z_{8 t} \text { and } z_{9 t} \text { are employed as state variables, where } u_{1 t} \text { corresponds to the } \\
\text { cointegrating relationship between } z_{4 t} \text { and } z_{5 t} \text {. }\end{array}$} \\
\hline STAR1 & 0.002 & 1.47 & -0.787 & -2.64 & $\Delta\left(z_{2 t-1}\right), z_{8 t-1}$ & -5.79 & -5.65 \\
\hline STAR2 & 0.003 & 2.82 & -0.726 & -2.54 & $u_{1 t-1}, \Delta\left(z_{2 t-1}\right)$ & -6.07 & -5.93 \\
\hline STAR3 & 0.003 & 3.78 & -0.803 & -2.98 & $u_{1 t-1, \Delta}\left(z_{2 t-1}\right), \Delta\left(z_{5 t-1}\right)$ & -6.29 & -6.14 \\
\hline STAR4 & 0.003 & 4.01 & -0.685 & -2.46 & $u_{1 t-1}, \Delta\left(z_{5 t-1}\right)$ & -6.28 & -6.14 \\
\hline STAR5 & 0.003 & 2.72 & -0.513 & -1.42 & - & -6.00 & -5.90 \\
\hline \multicolumn{8}{|c|}{ C: Regressions based on Ferson and Schadt (1996). $z_{1 t}, z_{2 t}, z_{6 t}, z_{8 t}$ and $z_{9 t}$ are employed as state variables. } \\
\hline STAR1 & 0.001 & 1.14 & -0.495 & -1.46 & $z_{8 t-1}$ & -5.77 & -5.66 \\
\hline STAR2 & 0.002 & 2.19 & -0.237 & -0.98 & $z_{8 t-1}$ & -6.03 & -5.91 \\
\hline STAR3 & 0.002 & 2.86 & -0.354 & -1.91 & & -6.25 & -6.15 \\
\hline STAR4 & 0.003 & 3.14 & -0.444 & -1.93 & & -6.25 & -6.15 \\
\hline STAR5 & 0.003 & 2.72 & -0.513 & -1.42 & & -6.00 & -5.90 \\
\hline
\end{tabular}

(ii) The first differences of the term spread variable $z_{2 t}$ appear to be statistically significant for the STAR1 and STAR2 portfolios under the assumption of zero cointegrating relationships (Table 3A), and for the STAR1, STAR2 and STAR3 portfolios, under the assumption of one cointegrating relationship (Table 3B).

(iii) The first differences of the Consumer Sentiment Index $z_{5 t}$ appear to be statistically significant for the STAR4 portfolio under no cointegration (Table 3A), and for the STAR3 and STAR4 portfolios under the assumption of one cointegrating relationship (Table 3B).

(iv) Although the first differences of the price of oil, $z_{3 t}$ and of the US dollar exchange rate, $z_{4 t}$ do not appear to be statistically significant under the assumption of no cointegration (Table 3A), under the assumption of one cointegrating relationship between $z_{3 t}$ and $z_{4 t}$, the corresponding residuals appear to statistically significant for the STAR2, STAR3 and STAR4 portfolios (Table 3B).

\section{Conclusions}

We introduced a methodology that allows for the estimation of models that derive from polynomial approximations of the time varying betas in conditional asset pricing models. We first showed that when some of the variables in the functional form of the betas are $I(1)$, the researcher must transform these variables in order to maintain stationarity of the right hand side of the assumed asset pricing model. The straightforward approach is to replace these variables with their first differences.

Our methodology provides an alternative treatment of the nonstationarity problem of the right hand side. Specifically, our approach makes use of possible cointegrating relationships between the variables in the functional forms of the conditional loadings. We show that by replacing the cointegrated variables with the corresponding residuals of the cointegrating relationship, we maintain the stationarity of the right hand side of the asset pricing model.

Next, we provided an example by applying our methodology to funds-of-funds which are based on the Morningstar mutual fund ranking system (see, e.g., Blake and Morey, 2000). Specifically, we considered a conditional CAPM (see Ferson and Schadt, 1996; Shanken, 1990) in which portfolio risk is a function of observed variables.

We showed that when the approach in Ferson and Schadt (1996) is used, only the dividend yield of the S\&P 500 appears to be a statistically significant factor in the specification of the conditional betas. By employing a broader set of candidate state variables for the specification of the betas, we proceeded by considering two cases. The first corresponded to no cointegration between the $I(1)$ variables. Interestingly, however, we identified a possible cointegrating relationship between two of the $I(1)$ variables, namely, the price of oil and the US dollar exchange rate. We showed that the residuals of this relationship appear to be statistically significant factors when they are used in the functional form of the betas. On the other hand, the first differences of both the price of oil and the US dollar exchange rate are not statistically significant when no cointegration is assumed.

The methodology presented in Section 2, along the results of the subsequent empirical study support the view that the residuals of cointegrating relationships between integrated variables in the specification of the conditional betas may reveal significant information about the dynamics of the betas. 


\section{Authors' contribution}

Antonios Antypas: conceptualization, software, investigation, data curation. Guglielmo Maria Caporale: conceptualization, supervision, writing - review \& editing. Nikolaos Kourogenis: conceptualization, methodology, formal analysis, writing - original draft, writing - review \& editing. Nikitas Pittis: conceptualization, methodology, writing - original draft.

\section{Appendix A. Supplementary data}

Supplementary data associated with this article can be found, in the online version, at https://doi.org/10.1016/j.ribaf.2019. 101148.

\section{References}

Blake, C.R., Morey, M.R., 2000. Morningstar ratings and mutual fund performance. J. Finan. Quant. Anal. 35, 451-483.

Blume, M.E., 1971. On the assessment of risk. J. Finance 26, 1-10.

Blume, M.E., 1975. Betas and their regression tendencies. J. Finance 30, 785-795.

Bos, T., Fetherston, T.A., 1992. Market model nonstationarity in the Korean Stock Market. In: Ghon Rhee, S., Chang, R.P. (Eds.), Pacific-Basin Capital Markets Research, Vol. III. North-Holland, Amsterdam.

Bos, T., Fetherston, T.A., 1995. Nonstationarity of the market model, outliers, and choice of the market rate of return. In: Bos, T., Ferson, T.A. (Eds.), Advances in Pacific-Basin Financial Markets 1. JAI Press.

Bos, T., Newbold, P., 1984. An empirical investigation of the possibility of stochastic systematic risk in the market model. J. Business 57, 35-41.

Chen, Q., Chi, Y., 2018. Smart beta, smart money. J. Emp. Finance 49, 19-38.

Clare, A., Sherman, M.B., Thomas, S., 2016. Multi-asset class mutual funds: can they time the market? Evidence from the US, UK and Canada. Res. Int. Business Finance 36, 212-221.

Collins, D.W., Ledolter, J., Rayburn, J.D., 1987. Some further evidence on the stochastic properties of systematic risk. J. Business 60, 425-448.

Dickey, D.A., Fuller, W.A., 1979. Distribution of the estimators for autoregressive time series with a unit root. J. Am. Stat. Assoc. 74, 427-431.

Fabozzi, F.J., Francis, J.C., 1978. Beta as a random coefficient. J. Finan. Quant. Anal. 13, 101-116.

Faff, R.W., Lee, J.H.H., Fry, T.R.L., 1992. Time stationarity of systematic risk: some Australian evidence. J. Business Finance Account. 19, 253-270.

Ferson, W.E., Schadt, R.W., 1996. Measuring fund strategy and performance in changing economic conditions. J. Finance 51, 425-461.

Fisher, L., Kamin, J.H., 1985. Forecasting systematic risk: Estimates of 'raw' beta that take into account the tendency of beta to change and the heteroscedasticity of residual returns. J. Finan. Quant. Anal. 20, 127-149.

Füss, R., Hille, J., Rindler, P., Schmidt, J., Schmidt, M., 2010. From rising stars and falling angels: on the relationship between the performance and ratings of German mutual funds. J. Wealth Manag. 13, 75-90.

Jagannathan, R., Wang, Z., 1996. The Conditional CAPM and the cross-section of expected returns. J. Finance 51, 3-53.

Jiang, G.J., Yao, T., Yu, T., 2007. Do mutual funds time the market? Evidence from portfolio holdings. J. Finan. Econ. 86, 724-758.

Johansen, S., 1991. Estimation and hypothesis testing of cointegration vectors in Gaussian vector autoregressive models. Econometrica 59, 1551-1580.

Lettau, M., Ludvigson, S., 2001. Resurrecting the (C)CAPM: a cross-sectional test when risk premia are time varying. J. Polit. Econ. 109 , $1238-1287$.

Lintner, J., 1965. The valuation of risk assets and the selection of risky investments in stock portfolios and capital budgets. Rev. Econ. Stat. 47, 13-37.

Merton, R.C., 1973. An intertemporal capital asset pricing model. Econometrica 41, 867-887.

Newey, W.K., West, K.D., 1994. Automatic lag selection in covariance matrix estimation. Rev. Econ. Stud. 61, 631-653.

Ohlson, J., Rosenberg, B., 1982. Systematic risk of the CRSP equal-weighted common stock index: a history estimated by stochastic-parameter regression. J. Business $55,121-145$

Phillips, P.C.B., 1991. Optimal inference in cointegrated systems. Econometrica 59, 283-306.

Phillips, P.C.B., Perron, P., 1988. Testing for a unit root in time series regression. Biometrika 75, 335-346.

Ross, S., 1976. The arbitrage theory of capital asset pricing. J. Econ. Theory 13, 341-360.

Shanken, J., 1990. Intertemporal asset pricing: an empirical investigation. J. Econometr. 45, 99-120.

Sharpe, W., 1964. Capital asset prices: a theory of market equilibrium under conditions of risk. J. Finance 19, 425-442.

Sunder, S., 1980. Stationarity of market risk: random coefficients tests for individual stocks. J. Finance 35, 883-896.

Treynor, J.L., 1962. Toward a Theory of Market Value of Risky Assets (Unpublished manuscript). Final Version in Korajczyk, R. A., ed. Asset Pricing and Portfolio Performance (1999). Risk Books, London, pp. 15-22.

Treynor, J., Mazuy, K., 1966. Can mutual funds outguess the market? Harv. Business Rev. 44, 131-136. 